Journal of the Egyptian Society of Parasitology, Vol.43, No.1, April 2013

J. Egypt. Soc. Parasitol., 43(1), 2013: 209 - 214

\title{
DESCRIPTION OF RHADINORHYNCHUS DORSOVENTROSPINOSUS (ACANTHOCEPHALA: RHADINORHYNCHIDAE) FROM THE RED SPOT EMPEROR LETHRINUS LENTJAN WITH NEW HOST AND LOCALITY RECORDS IN SAUDI ARABIA \\ By
}

Ali Othman Al Ghamdi

Department of Biology, College of Science, Al Baha University, Al Baha, Saudi Arabia

\begin{abstract}
Adult worms of Rhadinorhynchus dorsoventrospinosus (Acanthocephala: Rhadinor-hynchidae) were collected from the small intestine of the red spot emperor Lethrinus lentjan (family Lethrinidae) from locations along the Red Sea at Jeddah City, Saudi Arabia. Twenty three out of 70 fish specimens (32.9\%) were found to be naturally infected. The parasite was described using photo research Zeiss microscopy and a scanning electron microscope (SEM). Light microscopic studies revealed that the adult worm possessed a proboscis which was long, cylindrical with a uniform width measured $0.44 \pm 0.02(0.38-0.46) \mathrm{mm}$ in length and $0.12 \pm 0.02(0.09-0.15) \mathrm{mm}$ in width. Proboscis hooks observed by scanning electron microscopy were large, uniform in size (14-16 rows of 26 hooks each) with a row of longer hooks at the base. Comparison between the present described species and four species of the same genus was done, it was observed that there was only one comparable species, $R$. dorsoventrospinosus resembled the present parasite in the general morphology and differed from others, so the present studied species is classified as $R$. dorsoventrospinosus with new host and locality records.
\end{abstract}

Key words: Rhadinorhynchus dorsoventrospinosus, Rhadinorhynchidae, Lethrinus lentjan, light and scanning electron microscopy

\section{Introduction}

Members of phylum Acanthocephala are endoparasites without a digestive tract. They are slender or slightly flattened worms infecting mainly fish, birds and mammals. The diagnostic feature of the phylum is the organ of attachment consisting of an invaginable proboscis that forms the anterior end. This proboscis is armed with rows of recurved hooks, thus the common name of spiny-headed worms applied to these parasites (Hyman, 1951). The trunk is a hollow structure that contains excretory, reproductive and nervous system and is filled with pseudocoelomic fluid (Martins et al, 2001; Santos et al, 2005).

The other unique morphological features of acanthocephalans include a proboscis receptacle at the anterior end of the trunk and the paired lemnisci that extend into the trunk from the neck. Parasitism by acanthocephalans 
is frequently seen in intestines of wild fresh water and salt water fish. The irreversible mechanical damage caused by the attachment of the armed proboscis affect architecture of the intestinal tissues leading to pathological changes. Loss/degeneration of the intestinal villi, formation of the granular tissues and capsule formation associated with host immune responses which seriously affect the digestive and absorptive efficiency of the animal.

In heavy infections they can cause occlusion of the gut and invasion/ migration of parasites into uncommon locations (Nickol, 2006). The pathological consequences of parasitiosis of fishes are well documented and serve as evidence to support the view that parasites are one of the main causes of mortality in fish population. Diversity of acanthocephalans is limited to approximately 1150 described species.

Most species and genera of this family are recognized by the relatively large size and morphology of trunk. Morphological and morphometric characterizations of $R$. dorsoventrospinosus were described by the light and scanning electron microscopy from the red spot emperor, Lethrinus lentjan collected from coasts of the Red Sea at Jeddah City, Saudi Arabia with new host and locality records.

\section{Materials and Methods}

Seventy fish specimens of Lethrinus lentjan were collected and examined for acanthocephalan parasites. Samples were collected during the period from April to December 2012 from boat landing sites along the coasts of the
Red Sea and sometimes from the fish markets at Jeddah City, Saudi Arabia. The parasites were isolated from the intestine and pyloric ceca of the examined fish, transferred to a clean saline solution by using a brush or small pipettes and washed several times by saline solution to remove any mucous or debris which is usually adhere to their body surface. Acanthocephalans were relaxed in tap water, this was important for their proboscis to be fully everted from their bodies (Gibson, $1985)$ then fixed in $10 \%$ formalin. After fixation, the collected samples were washed in distilled water for 15 minutes to remove the excess fixative and then processed to staining which is carried out by using acetic acid alum carmine for 5-10 minutes (Carlton, 1967).

After staining, a differentiation step must be carried out to remove the excess stain by placing the stained worms into a dilute solution of acid alcohol $(0.5 \mathrm{ml}$ in $1000 \mathrm{ml}$ alcohol), it is better to carry out this process under a binocular dissecting microscope to detect the end point of differentiation. This is followed by dehydration in an ascending series of ethanol, $30 \%, 50 \%$, $70 \%, 90 \%, 95 \%$ and absolute ethanol, leaving the parasites for 2-5 minutes in each grade. The specimens were then cleared in xylene, then mounted in Canada balsam, covered with cover glass and left to dry in an oven at $40^{\circ} \mathrm{C}$. Drawings were made with the help of a Zeiss microscope supplied with a phase contrast unit. The prevalence, mean abundance and morphometric measurements followed the guidelines of Bush 
et al. (1997), minimum and maximum values were given, followed in parentheses by the arithmetic mean $( \pm \mathrm{SD})$. For scanning electron microscopy, specimens of pleurocerci were fixed in $4 \%$ buffered gluteraldehyde, washed in cacodylate buffer and dehydrated in an ascending alcohol series. After passing through an ascending series of the Genosolv-D, they were processed in a critical point drier "Bomer-900" with freon 13 and sputter coated with goldpalladium in a Technics Hummer $\mathrm{V}$ and examined with an Etec Autoscan at 20 kV Jeol scanning EM.

\section{Results}

Twenty three (32.9\%) out of 70 fish specimens were found to be naturally infected with acanthocephalan parasite Rhadinorhynchus dorsoventrospinosus Amin et al. (2011) belonging to family: Rhadinorhynchidae. The infection was recorded in the stomach and intestines of Lethrinus lentjan fish (Family: Lethrinidae).

Description: The parasites are clubshaped, elongated flukes, small to moderate in size with a long, cylindrical proboscis with a uniform width measured $0.44 \pm 0.02(0.38-0.46) \mathrm{mm}$ in length and $0.12 \pm 0.02(0.09-0.15) \mathrm{mm}$ in width (Figs.1-3). Proboscis hooks (Figs.3,5,6) were large and uniform in size (14-16 rows of 26 hooks each) with a row of longer hooks at the base. A few rows of small hooks were present on the anterior body region of the worm. Females were large and orange in color measured $10 \pm 2(8-11)$ $\mathrm{mm}$ and $0.80 \pm 0.02(0.78-0.83) \mathrm{mm}$ in maximum width. The general characte- ristics of the adult worm were the presence of trunk region which was long, uniformly cylindrical, spinose anteriorly with two fields. Anterior field was complete circles of 10-15 spines per circle with 2-4 dorsal and 13 ventral spines. The posterior field extended from just past proboscis receptacle to near mid trunk with 7-27 dorsal and 11-43 ventral spines. Neck prominent with a posterior ring of hooks (Figs. 7,8) measured $0.50 \pm 0.02$ $(0.47-0.58) \mathrm{mm}$ in length and with a posterior width $0.20 \pm 0.02(0.16-0.22)$ $\mathrm{mm}$. Proboscis receptacle was long, about twice as long as proboscis measured $0.93 \pm 0.02(0.90-0.95) \mathrm{mm}$ in length and $0.22 \pm 0.02(0.20-0.25) \mathrm{mm}$ in width, with a cephalic ganglion near its middle. Two lemnisci slightly subequal, digitiform, longer than proboscis receptacle measuring $1.40 \pm 0.02$ (1.31$1.42) \mathrm{mm}$ in length. Gonopore is subterminal in both sexes. Female trunk measures $7.05 \pm 0.02(6.81-7.12) \mathrm{mm}$ in length and $0.71 \pm 0.02(0.69-0.78) \mathrm{mm}$ in width. The eggs were scattered all over the body which are small elongated tapered at both ends (Fig. 4)

\section{Taxonomic summary:}

Family: Rhadinorhynchidae Travassos (1923).

Species: Rhadinorhynchus dorsoventrospinosus (Amin et al, 2011).

Host: The red spot emperor, Lethrinus lentjan (F: Lethrinidae Linnaeus, 1758) Infection site: Intestine \& pyloric ceca. Locality: Coasts of the Red Sea at Jeddah City, Saudi Arabia. 
Prevelance: Twenty three out of 70 fish specimens with a percentage of $32.9 \%$ were found to be naturally infected.

Etymology: Specific name is derived from the dorsoventral arrangement of trunk spines.

\section{Discussion}

The present specimen was classified as $R$. dorsoventrospinosus belonging to family Rhadinorhynchidae Travassos, (1923) according to the morphological features which agree with previous studies describing the same species with some measurement differences (tab. 1).

The four species of Rhadinorhynchus sp. have dorsal and ventral trunk spines in their posterior field were previously described from different host species, Rhadinorhynchus erumei (Gupta and Fatima, 1981), R. cadenati (Glovan and Houin, 1964; Glovan, 1969), R. lintoni (Cable and Linderoth, 1963) and R. dorsoventrospinosus (Amin et al, 2011). By comparison with the species of Rhadinorhynchus described herein, $R$. cadenati possessed a probos-cis which has more hook rows (14-16) and less hooks per row (25-26) with smaller egg size $(65-80 \times 17-20 \mu \mathrm{m})$ (Golvan, 1969).

In $R$. erumei, anterior trunk spines are more numerous (in 8-9 rings) and the posterior spines are fewer (in 5-6 rings) reaching a maximum of 22-25 in length, the proboscis has only 10 rows of 26 much smaller hooks each reachs a maximum of 26 long (Gupta and Fatima,1981). In $R$. lintoni, the dorsal trunk spines in the posterior field may be totally absent or may reach a maximum of 8 and the ventral spines may reach up to $16-17$. The proboscis of R.lintoni has 14-16 rows of hooks (compared to 11-12 in $R$. dorsoventrospinosus) each with 28-32 hooks.

Proboscis receptacle is consi-derably longer in $R$. lintoni $(6.1 \mathrm{~mm}$ long in males, $7.5 \mathrm{~mm}$ long in females (compared to $4.1 \mathrm{~mm}$ and $4.3 \mathrm{~mm}$ in $R$. dorsoventrospinosus) (Cable and Linderoth, 1963). So, thepresent species morphologically differed from the comparable one but resembles species described by Amin et al. (2011).

\section{Conclusion}

A comparative study between the measurements of $R$. dorsoventrospinosus (the present study) and those described from Decapterus kurroides, and another species $R$. celebesensis from Caranx sp. and Synagris sp., proved that the described species has a new host and locality records.

\section{References}

Amin, OM, Heckmann, A, Ha, NV, 2011: Description of two new species of Rhadinorhynchus(Acanthocephala, Rhadinorhynchidae) from marine fish in Halong Bay, Vietnam, with a key to species. Acta Parasitol. 56,1:67-77.

Bush, AO, Lafferty, KD, Lotz, JM, Shostak, AW, 1997: Parasitology meets ecology on its own terms: Margolis et al. revisited. J. Parasitol. 83:575-83.

Cable, RM, Linderoth, J, 1963: Taxonomy of some Acanthocephala from marine fishes with reference to species from Curacao, N.A., and Jamaica, W.I. J. Parasitol. 49:706-16.

Carlton, BC, 1967: Transformation mapping of the genes controlling tryp- 
tophan biosynthesis in Bacillus subtilis. J. Bacteriol. 94:660-5.

Gibson, JW, 1985: Satisfaction with upward and downward organizational communications: Another perspective. Proc. Southwest Academy of Management (March).

Golvan, YJ, 1969: Systematique des Acanthocephales (Acanthocephala Rudolphi, 1801). L'ordre des Palaeacanthocephala Meyer (1931). I. La superfamille des Echinorhynchoidea (Cobbold, 1876) Golvan YJ, Houin A. (1963) Memoire du Muséum National d'Histoire Naturelle, Nouvelle série. Série A: Zool. 57:1-373.

Gupta, VC, Fatima, S 1981: On three acanthocephalan parasites of fishes. Rev. Parassitol. 42:443-9.

Hyman, LH, 1951: Invertebrates: Acanthocephala, Aschelminthes \& Entroprocta. Mc-Graw Hill Pubisher, USA.

Martins, ML, Moraes, FR, Fujimoto,
RY, Onaka, EM, Quintana, CIF, 2001: Prevalence and histopathology of Neoechinorhynchus curemai Noronha, 1973 (Acanthocephala: Neoechinrhynchidae) in Prochilodus lineatus Valenciennes, 1836 from Volta Grande Resevoir, MG, Brazil. Braz. J. Biol. 61, 3:517-22.

Nickol, BB, 2006: Phylum Acanthocephala, In: Protozoan and Metazoan Infections; Fish Diseases and Disorders. Woo, P.T.K. (ed.), $2^{\text {nd }}$ Ed. Vol. I. CAB International, Wallingford.

Santos, RS, Martins, ML, Maregoni, NG, Francisco, CJ, Piazza, RS, et al, 2005: Neoechinorhynchus curemai (Acanthocephala:Neoechinrhynchidae) in Prochilodus lineatus (Osteichthyes: Prochilodontidae) from Parana River. Brazil. Vet. Parasitol. 134:111-5.

Yamaguti, S, 1953: Parasitic Worms mainly from Celebes. Part 3. Digenetic trematodes of Fishes, II. Acta Med. Okay. 8, 3:1-43.

Table 1: Comparative measurements $(\mathrm{mm})$ between female Radinorhynchus dorsoventrospinosus under study and previously described species:

\begin{tabular}{|l|c|c|c|}
\hline \multicolumn{1}{|c|}{$\begin{array}{c}\text { Parasite } \\
\text { Aspects }\end{array}$} & $\begin{array}{c}\text { R. celebesensis } \\
\text { (Yamaguti, 1953) }\end{array}$ & $\begin{array}{c}\text { R. dorsoventrospinosus } \\
\text { (Amin et al., 2011) }\end{array}$ & $\begin{array}{c}\text { R. dorsoventrospinosus } \\
\text { (Present study) }\end{array}$ \\
\hline Host & Caranx sp., Synagris sp. & Decapterus kurroides & Pagrus pagrus \\
\hline Trunk length & 6.25 & $17.5-37.75(26.04)$ & $7.05 \pm 0.02(6.81-7.12)$ \\
\hline Trunk width & 0.4 & $0.47-0.95(0.71)$ & $0.71 \pm 0.02(0.69-0.78)$ \\
\hline Neck length & 0.150 .32 & $0.426-0.499(0.462)$ & $0.50 \pm 0.02(0.47-0.58)$ \\
\hline Neck width & $0.3-0.32$ & $0.426-0.468(0.447)$ & $0.20 \pm 0.02(0.16-0.22)$ \\
\hline Proboscis length & $0.52-0.6$ & $2.50-2.74(2.60)$ & $0.44 \pm 0.02(0.38-0.46)$ \\
\hline Proboscis width & $0.28-0.4$ & $0.27-0.31(0.28)$ & $0.12 \pm 0.02(0.09-0.15)$ \\
\hline Proboscis receptacle length & $1.05-1.4$ & $3.87-4.75(4.31)$ & $0.93 \pm 0.02(0.90-0.95)$ \\
\hline Leminisci length & ------- & $3.54-4.27(3.90)$ & $1.40 \pm 0.02(1.31-1.42)$ \\
\hline
\end{tabular}

\section{Explanation of Figures}

Figs.1-4: Photomicrographs of adult female acanthcephalan parasite Radinrhynchus dorsoventrospinosus. 1 Whole mount preparation of worm with long slender proboscis (P), followed by neck region (NE). Proboscis housed within proboscis receptacle (PR) followed by two long leminisci (LI). Note: Scattered eggs (E) throughout body. 2-4 High magnifications of: 2 Anterior end of worm showing proboscis (P) equipped with spines (S), small neck (NE). 3 Basal region of proboscis (P) with curved spines (S). 4 Mid part showing elongated scattered eggs (E).

Figs.5-8: Scanning electron micrographs of adult showing high magnifications of 5 Anterior end of worm with long proboscis $(\mathrm{P})$ armed with spines. 6 Apical region of proboscis $(\mathrm{P})$ with hollow curved spines $(\mathrm{S})$. 7,8 Neck region showing numerous spines( $\mathrm{S})$ covering this region. 


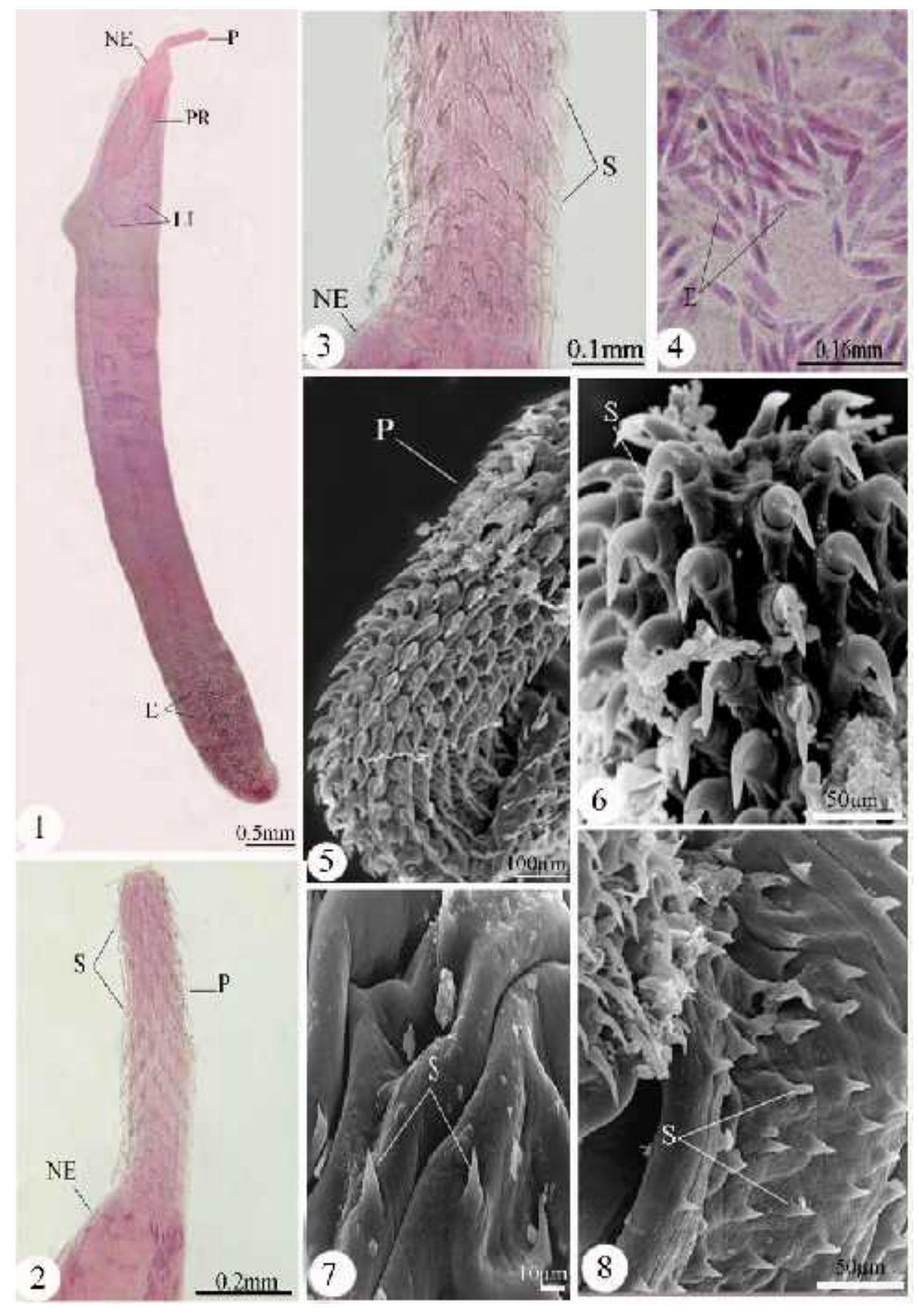

